OPEN ACCESS

Edited by:

Rubina Sirri,

Università degli Studi di Bologna, Italy

Reviewed by:

Fabio Marino,

Università degli Studi di Messina, Italy Begum Yurdakok Dikmen, Ankara University, Turkey

*Correspondence:

Gionata De Vico gionata.devico@unina.it

Specialty section:

This article was submitted to

Aquatic Physiology,

a section of the journal

Frontiers in Physiology

Received: 06 February 2018

Accepted: 12 March 2018

Published: 26 March 2018

Citation:

De Vico G, Guida V and Carella F (2018) Urtica dioica (Stinging Nettle):

A Neglected Plant With Emerging

Growth Promoter/Immunostimulant

Properties for Farmed Fish.

Front. Physiol. 9:285.

doi: 10.3389/fphys.2018.00285

\section{Urtica dioica (Stinging Nettle): A Neglected Plant With Emerging Growth Promoter/Immunostimulant Properties for Farmed Fish}

\author{
Gionata De Vico ${ }^{1 *}$, Vincenzo Guida ${ }^{2}$ and Francesca Carella ${ }^{1}$ \\ ${ }^{1}$ Department of Biology, University of Naples Federico II, Naples, Italy, ${ }^{2}$ Calatia Agricultural Society, Caserta, Italy
}

Urtica dioica (stinging nettle), is a perennial plant belonging to the family of Urticaceae, genus Urtica. Despite the use of nettle in folk veterinary medicine is well documented, $U$. dioica is today an underestimated and frequently neglected plant, considered by the contemporary agriculture as a weed to be eliminated. This mini review focus on very recent studies on dietary administration of $U$. dioica, both as a single herb or in combination with other herbs, to enhance growth and stimulate farmed fish immunity, thus enabling the fish to be more resistant against bacterial infections. Such an emerging feature, together with cost-effectiveness, adequate availability, and easy processing of nettle, could make this herb an excellent, inexpensive and widely used dietary supplement on intensive fish farms.

Keywords: Urtica dioica, growth promoter, immunostimulant, farmed fish, nettle

\section{INTRODUCTION}

Immunostimulants and growth promoters consisting of herbs or their extracts, are frequently administered to farmed fishes (Harikrishnan et al., 2011; Chakraborty et al., 2013; Van Hai, 2015). In fact, when added to diet, they have proven to be effective in a dose dependent manner in stimulating their immune system and improving growth performances (Harikrishnan et al., 2011; Chakraborty et al., 2013; Van Hai, 2015; Vallejos-Vidal et al., 2016). According to Reverter et al. (2017) plants belonging to the order Lamiales (family Lamiaceae) are the most studied for their application in aquaculture, and had the highest number of species displaying immunostimulant activity. However, $U$. dioica, a polyvalent plant belonging to the order Rosales, that has a long history of traditional medicinal uses in many countries in the world (Ahmed and Parasuraman, 2014), seems to possess unexpected biological properties useful also for aquaculture. Such an emerging feature, together with cost-effectiveness, adequate availability, and easy processing, could make this herb an excellent, inexpensive and widely used dietary supplement on intensive farms. Unfortunately, despite its great potentials as multi-purpose crop under a low input cultivation, $U$. dioica is today an underestimated and frequently neglected plant, considered by the contemporary agriculture as a weed to be eliminated (Di Virgilio et al., 2015). Furthermore, the literature concerning its use in fishes is still fragmentary, which could limit the effort for studying the application of this plant in aquaculture. This mini review focus on very recent studies on dietary administration of $U$. dioica, both as a single herb or in combination with other herbs, to enhance growth and stimulate farmed fish immunity, thus enabling the fish to be more resistant against bacterial infections. 


\section{BOTANICAL PHARMACOLOGY OF U. DIOICA}

Urtica dioica (stinging nettle), is a perennial plant belonging to the genus Urtica of the family Urticaceae (Ahmed and Parasuraman, 2014). The stem is erect and green, quadrangular, with lacunar collenchyma at each corner. Fibrovascular bundles could be 12-20 (Corsi and Masini, 1997). The leaves are darkgreen above and paler beneath, oblong or ovate, opposite, cordate at the base, finely toothed (Testai et al., 2002). Stinging trichomes cover both stems and leaves, and contain a fluid enriched in histamine, acetylcholine, and serotonin (Tuberville et al., 1996). The small dioecious flowers are either male or female in separate inflorescences, brown to greenish in color, occurring as racemes in the axils of the upper leaves and flowering from May to September every year (Corsi and Masini, 1997; Ahmed and Parasuraman, 2014). A rhizome is present and the root is usually biarch (Corsi and Masini, 1997). Flavonoids, tannins, volatile compounds, fatty acids, polysaccharides, isolectins, sterols, terpenes, protein, vitamins, and minerals are among the main chemical constituents of $U$. dioica (Joshi et al., 2014). In this context, flavonoids and caffeic acid derivatives contribute to the anti-inflammatory, antioxidant and analgesic activities of Urtica leaves extracts (Chrubasik et al., 2007a). In particular, the anti-inflammatory effect of ethanolic extracts of $U$. dioica leaves is caused by inhibition of NF-kB pathway, which ultimately regulates inflammatory cytokine release (Chrubasik et al., 2007a). On the other hand, patient with benign prostatic hyperplasia (BPH) may benefit from nettle root extracts treatment thanks to at least three different mechanisms: (1) Lignans from an aqueous nettle root extract that inhibit the binding of Sex Hormone Binding Globulin (SHBG) to receptors on human prostatic membranes, which are involved in $\mathrm{BPH}$ pathogenesis (Chrubasik et al., 2007b; EMA, 2012); (2) chemicals found in a heptane fraction of $U$. dioica extracts inhibited aromatization of androstenedione, thus interfering with the conversion of testosterone into estrogen, a well-known mechanism in $\mathrm{BPH}$ pathogenesis (Chrubasik et al., 2007b; EMA, 2012); and (3) inhibition of aromatase gene expression may also be involved in the nettle root effect (Chrubasik et al., 2007b; EMA, 2012). The immunomodulating activity of $U$. dioica seems to be ascribable to its polysaccharide and lectin fractions, able to stimulate proliferation and interferon secretion of human lymphocytes (EMA, 2012). Finally, from a nutritional point of view, U. dioica leaves contain considerable amounts of essential amino acids, essential fatty acids, minerals, and vitamins (Rutto et al., 2013).

\section{ETHNOVETERINARY USE OF U. DIOICA}

The use of nettle in folk veterinary medicine is well documented and it is difficult to give an exhaustive view in this short paper. Briefly, in Europe, ethno-veterinary reports documented the use of U. dioica at least in Italy, Switzerland, Spain, and Austria (Disler et al., 2014). In Italy and Spain U. dioica was administered to chickens and turkeys as growth promoter and to stimulate hens to lay (Viegi et al., 2003; Bonet and Valles, 2007; Benítez et al., 2012). In some Italian regions, pigs were fed with boiled nettle to improve their resistance to infectious diseases; furthermore, $U$. dioica tips along with Malva sylvestris were also given to cows as a decoction after calving (Viegi et al., 2003). In Switzerland, stinging nettle orally administered to animals (both as raw material and infusion), improves general strengthening and is used for curing genital, gastrointestinal, skin and metabolic disorders (Disler et al., 2014). U. dioica is also used in traditional veterinary medicine in Canada, where it is given to ruminant to improve fertility and in pregnant and lactating ones to provide trace minerals and as tonic (Lans et al., 2007). In India, animal disorders, such as haematuria, rheumatism, neck sore, infertility, bone fracture, wounds, sprains, lactation, abdominal pain, and internal injury, are also cured with nettle (Pande et al., 2007).

\section{U. DIOICA AS GROWTH PROMOTER AND IMMUNOSTIMULANT IN FISH}

Bacterial infections are considered the major cause of growth retardation and/or mortality in aquaculture for which prevention is the most important measure (Madhuri et al., 2012).

Most of the studies concerning the use of $U$. dioica as growth promoter and immunostimulant in fish, involved species of either economic interest, such as Oncorhynchus mykiss, or endangered (Labeo victorianus, Huso huso) and even ornamental fish (Carassius auratus).

\section{Urtica dioica as Immunostimulant and Growth Promoter in O. mykiss}

Major producing countries of O. mykiss include Chile, Italy, Norway, France, Spain, Denmark, Germany, Iran, USA, and the UK. In 2015 the global aquaculture production of O. mykiss reached about 762,000 tons (FAO, 2017).

According to Awad and Austin (2010) feeding Rainbow trout with a diet including $1 \%$ stinging nettle significantly reduce mortalities after challenge with Aeromonas hydrophila. Furthermore, in the group fed $U$. dioica they also reported an increase in values of haematocrit, hemoglobin, antiprotease, total protein, serum bactericidal activity, respiratory burst, myeloperoxidase, complement, and lysozyme activity (Awad and Austin, 2010).

More recently, Saeidi asl et al. (2017) demonstrated that $O$. mykiss juveniles receiving $3 \% \quad U$. dioica dietary supplementation improved weight gain, growth rate and feed conversion ratio. Furthermore, hematological responses including: haematocrit (Htc), hemoglobin ( $\mathrm{Hb}$ ), lymphocyte, neutrophil populations, and total red blood cells, mucus bactericidal activity, significantly increased after 8 weeks in the nettle group (Saeidi asl et al., 2017). In the same experiment the cumulative mortality of rainbow trout juveniles subjected to Yersinia ruckeri infection exhibited a significantly low mortality levels in $U$. dioica group compared to controls, suggesting that dietary administration of $U$. dioica enhanced growth and stimulated fish immunity (Saeidi asl et al., 2017).

Awad et al. (2012) also demonstrated that feeding rainbow trout for 2 months with a diet containing 1-2\% of a mixture of herbs (Lupinus perennis, Mangifera indica, and U. dioica) 
resulted in weight gain, fish length and growth rate significantly higher in treated fish than in control ones. Immune parameters such as lysozyme, antiprotease, total protein, myeloperoxidase, bactericidal activity, and IgM titers were also enhanced by adding $1 \%$ nettle extract (Quercetin) to trout diet (Awad et al., 2013).

Bilen et al. (2016), fed three different groups of trout for 30 days with diets containing three different concentrations of a nettle extract. At the end of the feeding trial, rainbow trout were challenged with $A$. hydrophila, resulting in a fish weight, growth rate, and survival rate higher in treated groups than in control group (Bilen et al., 2016). Furthermore, all measured immune parameters improved after dietary administration of nettle extract, with a significantly higher level of phagocytic, lysozyme and myeloperoxidase activity compared to control (Bilen et al., 2016).

\section{Urtica dioica Studies in Labeo victorianus and Beluga sturgeon (Huso huso), Two "Critically Endangered Species" of Economic and Social Relevance}

Currently, L. victorianus and Beluga sturgeon (H. huso) are both listed at the International Union for Conservation of Nature (IUCN) as "critically endangered species" (Maithya et al., 2005; Gesner et al., 2010; FishBase team RMCA Geelhand, 2016).

As far as L. victorianus is concerned, before the 1950s, it was a fished species of major commercial value in Lake Victoria (Ogutu-Ohwayo, 1990; Kembenya et al., 2017). Unfortunately, a combination of factors, including illegal fishing, overfishing, as well as competition with invasive alien species, led to a rapid collapse of the population in the late 1950s (Ogutu-Ohwayo, 1990; Kembenya et al., 2017). Currently, Kenya government supports aquaculture projects of this species in attempt to reduce the exploitation of residual natural populations and promote restocking (Kembenya et al., 2017). In this context, juveniles and adults of $L$. victorianus were challenged against $A$. hydrophila to assess the effect on growth performance and immune parameters of $5 \% U$. dioica dietary supplementation of for 16 weeks (Ngugi et al., 2015). In particular, serum immunoglobulins, lysozyme activity and respiratory burst significantly increased, with fish survival reaching up to $95 \%$ after the bacterial challenge, a percentage significantly higher compared to the control group (Ngugi et al., 2015). Furthermore, adding nettle to diet, increased growth performance, hematological (red blood cell count [RBC], white blood cell counts [WBC], haematocrit [Hct], mean cell hemoglobin concentration $[\mathrm{Hb}]$ ), biochemical (total serum protein and albumin), and immunological parameters in experimental fishes (Ngugi et al., 2015).

Historical data reported that the Beluga sturgeon (H. huso) used to live in the Pô river (Italy), in the Adriatic Sea and in the Danube river (Billard and Lecointre, 2001). In the last 40 years, stocks of sturgeons are dramatically decreasing due to overfishing and environmental degradation (Billard and Lecointre, 2001). Because of this decline, sturgeon aquaculture have been developed which hopefully may contribute to reduce fishing pressure and increase wild stocks (Bronzi et al., 2011). However, development of sturgeon farming was also accompanied by disease outbreaks, including those unknown prior to cultivation (Bauer et al., 2002). For that reason, lately, increased attention has been directed toward the use of immunostimulant in Beluga sturgeon aquaculture, in order to improve fish health (Jalali et al., 2009).

In this context, Binaii et al. (2014) found that feeding beluga juveniles for 8 weeks with increasing amount of nettle in the diet $(0-12 \%)$ resulted in a significant increase in neutrophils and $\mathrm{Hb}$ levels compared to the controls. Furthermore, the increase of the above parameters was dose-dependent, with $12 \%$ nettle group showing the highest $\mathrm{Hb}, \mathrm{RBC}, \mathrm{WBC}$, Hct, respiratory burst activity, total immunoglobulin, and total protein values (Binaii et al., 2014). Other studies of Nobahar et al. (2015) the effect of $1 \%$ U. dioica diet supplementation on juveniles of Beluga sturgeon with mean weight of $30 \pm 0.5 \mathrm{~g}$ reared for resettlement. After 60 days treatment, Condition Factor, $\mathrm{Hb}$ concentration, Hct value, Neutrophils and Lymphocytes were significantly higher in fish fed nettle than in control group.

\section{Ornamental Fish}

Production of aquarium fish is becoming an important business activity in aquaculture because of an incessant increase in demand for ornamental fishes by hobbyists from all over the world (Yanar et al., 2008). Unfortunately, as with other types of breeding, one of the major limiting factors is infectious and parasitic diseases (Kumar et al., 2013). In this regard, Bilen et al. (2014) demonstrated that supplementing diet with $0.5 \mathrm{~g} / \mathrm{kg}$ of a methanolic extract of $U$. dioica for 30 days is sufficient to increase non-specific immune response of gold fish (C. auratus) with an increased superoxide anion production, lysozyme, myeloperoxidase, and phagocytic activity.

\section{CONCLUSION}

Among the food production sectors, aquaculture is the fastest growing in the world, and is expected to be the biggest source of food by the year 2030 (Brugère and Ridler, 2004; Carella and Sirri, 2017). Such an increase in fish farming, results in a parallel increase in outbreaks of infectious and metabolic diseases, which act as major limiting factors for aquaculture development (Wunderlich et al., 2017). In order to control mortality and avoid huge economic losses, fish farmers frequently adopt inappropriate practices, which disregard care for the environmental, animal and human health. Among them, the indiscriminate use of pesticides, disinfectants and antibiotics is of major concern (Valladão et al., 2015). For the above reasons, attention to a much more "natural" approach in aquaculture development is increasing worldwide (Xie et al., 2013). According to organic standards, health of the cultivated organisms shall be mainly guaranteed through preventive measures (i.e., optimizing management, feed, and diet). However, studies suggested that the use of disinfectants and antibiotics are not always effective in prevention or control diseases in aquaculture (Kumar et al., 2013). For that reason, to improve fish immunity and increase resistance to infectious diseases, immunostimulant are today routinely administered in fish farming (Kumar et al., 2013; Nobahar et al., 2015). However, 
the high cost of such additives and their impact on ecosystem health, risks becoming deterrent to their use, and the search for cheaper and more natural compounds is an urgent necessity for modern aquaculture. In this context, large numbers of plants have been proven to be rich sources of cheaper immune-enhancing and growth promoter substances, with a wide therapeutic and preventive spectrum of activity, potentially useful in solving the multiple health problems that characterize aquaculture (Karatas et al., 2003; Kumar et al., 2013). According to our knowledge, the effects of dietary nettle as growth promoter and immunostimulant in fish were examined in this brief survey. The review of the literature, thought limited, provides evidence for the effective immunostimulant use of nettle in aquaculture, and open new perspective for the use of $U$. dioica as cost-effective adjuvant therapy added to fish food to prevent

\section{REFERENCES}

Ahmed, M. K. K., and Parasuraman, S. (2014). Urtica dioica L., (Urticaceae): a stinging nettle. Syst. Rev. Pharm. 5, 6-8. doi: 10.5530/srp.2014.1.3

Awad, A., and Austin, B. (2010). Use of lupin (Lupinus perennis), mango (Mangifera indica) and stinging nettle (Urtica dioica) as feed additives to prevent Aeromonas hydrophila infection in rainbow trout (Oncorhynchus mykiss, Walbaum). J. Fish Dis. 33, 413-420. doi: 10.1111/j.1365-2761.2009.01133.x

Awad, E., Austin, B., and Lyndon, A. (2012). Effect of dietary supplements on digestive enzymes and growth performance of rainbow trout (Oncorhynchus mykiss, Walbaum). J. Am. Sci. 8, 858-864. doi: 10.7537/marsjas081212.119

Awad, E., Austin, D., and Lyndon, A. R. (2013). Effect of black cumin seed oil (Nigella sativa) and nettle extract (Quercetin) on enhancement of immunity in rainbow trout, Oncorhynchus mykiss (Walbaum). Aquaculture 388-391, 193-197. doi: 10.1016/j.aquaculture.2013.01.008

Bauer, O. N., Pugachev, O. N., and Voronin, V. N. (2002). Study of parasites and diseases of sturgeons in Russia: a review. J. Appl. Ichthyol. 18, 420-429. doi: 10.1046/j.1439-0426.2002.00422.x

Benítez, G., González-Tejero M. R., and Molero-Mesa, J. (2012). Knowledge of ethnoveterinary medicine in the Province of Granada, Andalusia, Spain. J. Ethnopharmacol. 139, 429-439. doi: 10.1016/j.jep.2011.11.029

Bilen, S., Ünal, S., and Güvensoy, H. (2016). Effects of oyster mushroom (Pleurotus ostreatus) and nettle (Urtica dioica) methanolic extracts on immune responses and resistance to Aeromonas hydrophila in rainbow trout (Oncorhynchus mykiss). Aquaculture 454, 90-94. doi: 10.1016/j.aquaculture.2015.12. 010

Bilen, S., Soydas, E., Bilen, A. M. (2014). Effects of methanolic extracts of nettle (Urtica dioica) on non-specific immune response of gold fish (Carassius auratus). Alinteri J. Agric. Sci. 27, 24-28.

Billard, R., and Lecointre, G. (2001). Biology and conservation of sturgeon and paddlefish. Rev. Fish Biol. Fish. 10, 355-392. doi: 10.1023/A:101223 1526151

Binaii, M., Ghiasi, M., Farabi, S. M. V., Pourgholam, R., Fazli, H., Safari, R., et al. (2014). Biochemical and hemato-immunological parameters in juvenile beluga (Huso huso) following the diet supplemented with nettle (Urtica dioica). Fish Shell. Immun. 36, 46-51. doi: 10.1016/j.fsi.2013.10.001

Bonet, M. A., and Vallès, J. (2007). Ethnobotany of Montseny biosphere reserve (Catalonia, Iberian Peninsula): plants used in veterinary medicine. J. Ethnopharmacol. 110, 130-147. doi: 10.1016/j.jep.2006.09.016

Bronzi, P., Rosenthal, H., and Gessner, J. (2011). Global sturgeon aquaculture production. J. Appl. Ichthyol. 27, 169-175. doi: 10.1111/j.1439-0426.2011.01757.x

Brugère, C., and Ridler, N. (2004). Global Aquaculture Outlook in the Next Decades: An Analysis of National Aquaculture Production Forecasts to 2030. FAO Fisheries Circular No. 1001. Rome: FAO. diseases and increase growth. However, the biological properties reviewed in this paper, perhaps represent only the tip of the iceberg of possible uses of nettle in aquaculture: some recent studies show, for example, the great efficacy of nettle extracts against the main pathogenic bacteria for fish in aquaculture (Dar et al., 2012). Thus, it is hopeful that further studies involving determination of optimal doses, the active principle of the plant extract and feeding protocols for food additives could led to widespread application of $U$. dioica in current aquaculture.

\section{AUTHOR CONTRIBUTIONS}

All authors listed have made a substantial, direct and intellectual contribution to the work, and approved it for publication.

Carella, F., and Sirri, R. (2017). Editorial: fish and shellfish pathology. Front. Mar Sci. 4:375. doi: 10.3389/fmars.2017.00375

Chakraborty, S. B., Horn, P., and Hancz, C. (2013). Application of phytochemicals as growth-promoters and endocrine modulators in fish culture. Rev. Aquacult. 5, 1-19. doi: 10.1111/raq.12021

Chrubasik, J. E., Roufogalis, B. D., Wagner, H., Sigrun, A., and Chrubasik, S. A. (2007a). A Comprehensive review on nettle effect and efficacy profiles, Part I: herba urticae. Phytomedicine. 14, 423-435. doi: 10.1016/j.phymed.2007.03.004

Chrubasik, J. E., Roufogalis, B. D., Wagner, H., and Chrubasik, A. (2007b). Comprehensive review on the stinging nettle effect and efficacy profiles. Part II: Urticae radix. Phytomedicine 14, 568-579. doi: 10.1016/j.phymed.2007. 03.014

Corsi, G., and Masini, A. (1997). Anatomical and ecological aspect in Italian taxa of the genus ortica. Atti Soc. Tosc. Sci. Nat. Mem. Ser. B 104, 1-8.

Dar, S. A., Ganai, F. A., Yousuf, A. R., Balkhi, M. H., Bhat, T. M., and Bhat, F. A. (2012). Bioactive potential of leaf extracts from Urtica dioica L. against fish and human pathogenic bacteria. Afr. J. Microbiol. Res. 6, 6893-6899. doi: 10.5897/AJMR12.336

Disler, M., Ivemeyer, S., Hamburger, M., Vogl, C. R., Tesic, A., Klarer, F., et al. (2014). Ethnoveterinary herbal remedies used by farmers in four north-eastern Swiss cantons (St. Gallen, Thurgau, Appenzell Innerrhoden and Appenzell Ausserrhoden). J. Ethnobiol. Ethnomed. 10:32. doi: 10.1186/1746-4269 $-10-32$

Di Virgilio, N., Papazoglou, E. G., Jankauskiene, Z., Di Lonardo, S., Praczyk, M., and Wielgusz, K. (2015). The potential of stinging nettle (Urtica dioica L.) as a crop with multiple uses. Indust. Crops Prod. 68, 42-49. doi: 10.1016/j.indcrop.2014.08.012

European Medical Agency (EMA). (2012). Assessment Report on Urtica dioica L., Urtica urens L., Their Hybrids or Their Mixtures, Radix. Available on line at: http://www.ema.europa.eu/docs/en_GB/document_library/Herbal_- HMPC_assessment_report/2012/11/WC500134484.pdf

FAO (2017). Fishery and Aquaculture Statistics. FAO Yearbook of Fisheries Statistics 2015. Food and Agriculture Organization of the United Nations. Available online at: http://www.fao.org/3/a-i7989t.pdf

FishBase team RMCA and Geelhand, D. (2016). Labeo victorianus. The IUCN Red List of Threatened Species. e.T60318A47182908. doi: 10.2305/IUCN.UK.2016-3.RLTS.T60318A47182908.en

Gesner, J., Chebanov, M., and Freyhof, J. (2010). Huso huso. The IUCN Red List of ThreatenedSpecies. e.T10269A3187455. doi: 10.2305/IUCN.UK.2010-1.RLTS.T10269A3187455.en

Harikrishnan, R., Balasundaram, C., and Heo, M.-S. (2011). Impact of plant products on innate and adaptive immune system of cultured finfish and shellfish. Aquaculture 317, 1-15. doi: 10.1016/j.aquaculture.2011.03.039

Jalali, M. A., Ahmadifar, E., Sudagar, M., and Takami, G. A. (2009). Growth efficiency, body composition, survival and haematological changes in great sturgeon (Huso huso Linnaeus, 1758) juveniles fed diets 
supplemented with different levels of Ergosan. Aquacult. Res. 40, 804-809. doi: 10.1111/j.1365-2109.2009.02166.x

Joshi, B. C., Mukhija, M., and Kalia, A. N. (2014). Pharmacognostical review of Urtica dioica L. Int. J. Green Pharm. 8, 201-209. doi: 10.4103/0973-8258. 142669

Karatas, S., Dügenci, N., and Akin, A. (2003). Some medicinal plants as immunostimulant for fish. Can. J. Ethnopharmacol. 88, 99-106. doi: 10.1016/S0378-8741(03)00182-X

Kembenya, E. M., Marcial, H. S., Nicholas, O., Outa, N. O., Sakakura, Y., and Hagiwara, A. (2017). Captive breeding of threatened African Carp, Labeo victorianus, of Lake Victoria. J. World Aquacult. Soc. 48, 955-962. doi: 10.1111 jwas. 12328

Kumar, S., Raman, R. P., Pandey, P. K., Mohanty, S., Kumar, A., and Kumar, K. (2013). Effect of orally administered azadirachtin on nonspecific immune parameters of goldfish Carassius auratus (Linn. 1758) and resistance against Aeromonas hydrophila. Fish Shell. Immunol. 34, 564-573. doi: 10.1016/j.fsi.2012.11.038

Lans, C., Turner, N., Khan, T., Brauer, G., and Boepple, W. (2007). Ethnoveterinary medicines used for ruminants in British Columbia. Can. J. Ethnobiol. Ethnomed. 3:11. doi: 10.1186/1746-4269-3-11

Madhuri, S., Mandloi, A. K., Govind, P., and Sahni, Y. P. (2012). Antimicrobial activity of some medicinal plants against fish patholgens. Int. Res. J. Pharm. 3, 28-30.

Maithya, J., Charo, H., Okeyo-Owuor, J. B., Wangila, B. C. C., Ouma, H., Orinda, C., et al. (2005). "Aquaculture strategy for restoration of threatened Lake Victoria fishes: the case for Oreochromis variabilis (Boulenger, 1906) and Labeo victorianus (Boulenger, 1901)," in Knowledge and Experiences Gained From Managing the Lake Victoria Ecosystem, eds G. A. Mallya, F. F. Katagira, G. Kanggoha, S. B. Mbwana, E. F. Katunzi, J. T. Wambende, N. Azza, E. Wakwabi, S. W. Njoka, M. Kusewa, and H. Busulwa (Dar es Salaam: Lake Victoria Environmental Management Project), 445-466.

Ngugi, C. C., Oyoo-Okoth, E., Mugo-Bundi, J., Orina, P. S., Chemoiwa, E. J., and Aloo, P. A. (2015). Effects of dietary administration of stinging nettle (Urtica dioica) on the growth performance, biochemical, hematological and immunological parameters in juvenile and adult Victoria Labeo (Labeo victorianus) challenged with Aeromonas hydrophila. Fish. Shellfish Immunol. 44, 533-541. doi: 10.1016/j.fsi.2015.03.025

Nobahar, Z. H., Gholipour-Kanani, H., Kakoolaki, S. H., and Jafaryan, H. (2015). Effect of garlic (Allium sativum) and nettle (Urtica dioica) on growth performance and hematological parameters of beluga (Huso huso). Iran. J. Aquat. Anim. Health 1, 63-69. doi: 10.18869/acadpub. ijaah.1.1.63

Ogutu-Ohwayo, R. (1990). The decline of the native fishes of Lakes Victoria and Kyoga (East Africa) and the impact of introduced species, especially the Nile perch, Lates niloticus and the Nile tilapia, Oreochromis niloticus. Environ. Biol. Fish. 27, 81-90. doi: 10.1007/BF00001938

Pande, P. C., Lalit Tiwari, L., and Pande, H. C. (2007). Ethnoveterinary plants of Uttaranchal-A review. Ind. J. Trad. Know. 6, 444-458.

Reverter, M., Tapissier-Bontemps, N., Sasal, P., and Saulnier, D. (2017). "Use of medicinal plants in aquaculture," in Diagnosis and Control of Diseases of Fish and Shellfish, 1st Edn, eds B. Austin and A. Newaj-Fyzul (Chichester, UK: John Wiley \& Sons Ltd), 223-261. doi: 10.1002/97811191 52125.ch9
Rutto, L. K., Xu, Y., Ramirez, E., and Brandt, M. (2013). Mineral properties and dietary value of raw and processed stinging nettle (Urtica dioica L.). Int. J. Food Sci. 2013:857120. doi: 10.1155/2013/857120

Saeidi Asl, M. R., Adel, M., Caipang, C. M. A., and Dawood, M. A. O. (2017). Immunological responses and disease resistance of rainbow trout (Oncorhynchus mykiss) juveniles following dietary administration of stinging nettle (Urtica dioica). Fish Shell. Immunol. 71, 230-238. doi: 10.1016/j.fsi.2017.10.016

Testai, L., Chericoni, S., Calderone, V., Nencioni, G., Nieri, P., Morell, I., et al. (2002). Cardiovascular effects of Urtica dioica L. (Urticaceae) roots extracts: in vitro and in vivo pharmacological studies. J. Ethnopharmacol. 81, 105-109. doi: 10.1016/S0378-8741(02)00055-7

Tuberville, T. D., Dudley, P. G., and Pollard, A. J. (1996). Responses of invertebrate herbivores to stinging trichomes of Urtica dioica and Laportea canadensis. Oikos 75, 83-88. doi: 10.2307/3546324

Valladão, G. M., Gallani, S. U., and Pilarski, F. (2015). Phytotherapy as an alternative for treating fish disease. J. Vet. Pharmacol. Ther. 38, 417-428. doi: 10.1111 /jvp.12202

Vallejos-Vidal, E., Reyes-López, F., Teles, M., and MacKenzie, S. (2016). The response of fish to immunostimulant diets. Fish Shell. Immunol. 56, 34-69. doi: 10.1016/j.fsi.2016.06.028

Van Hai, N. (2015). The use of medicinal plants as immunostimulants in aquaculture: a review. Aquaculture 446, 88-96. doi: 10.1016/j.aquaculture.2015.03.014

Viegi, L., Pieroni, A., Guarrera, P. M., and Vangelisti, R. (2003). A review of plants used in folk veterinary medicine in Italy as basis for a databank. $J$. Ethnopharmacol. 89, 221-224. doi: 10.1016/j.jep.2003.08.003

Wunderlich, A. C., de Oliveira Penha Zica, E., dos Santos Ayres, V. F., Guimarães, A. C., and Takeara, R. (2017). "Plant-derived compounds as an alternative treatment against parasites. in fish farming: a review," in Natural Remedies in the Fight Against Parasites, eds H. Khater, M. Govindarajan, and G. Benelli (InTech), 246. doi: 10.5772/67668. Available online at: https://www.intechopen. $\mathrm{com} /$ books/natural-remedies-in-the-fight-against-parasites/plant-derivedcompounds-as-an-alternative-treatment-against-parasites-in-fish-farminga-review

Xie, B., Qin, J., Yang, H., Wang, X., Wang,Y.-H., and Li, T. (2013). Organic aquaculture in China: a review from a global perspective. Aquaculture 414-415, 243-253. doi: 10.1016/j.aquaculture.2013.08.019

Yanar, M., Erçen, Z., Hunt, A. Ö., and Büyükçapar, H. M. (2008). The use of alfalfa, Medicago sativa as a natural carotenoid source in diets of goldfish, Carassius auratus. Aquaculture 284, 196-200. doi: 10.1016/j.aquaculture.2008.07.050

Conflict of Interest Statement: The authors declare that the research was conducted in the absence of any commercial or financial relationships that could be construed as a potential conflict of interest.

Copyright (c) 2018 De Vico, Guida and Carella. This is an open-access article distributed under the terms of the Creative Commons Attribution License (CC $B Y)$. The use, distribution or reproduction in other forums is permitted, provided the original author(s) and the copyright owner are credited and that the original publication in this journal is cited, in accordance with accepted academic practice. No use, distribution or reproduction is permitted which does not comply with these terms. 